\title{
Fibrin Sealants in Dura Sealing: A Systematic Literature Review
}

\author{
Felice Esposito ${ }^{10} *$, Filippo Flavio Angileri ${ }^{1 \oplus}$, Peter Kruse ${ }^{2 \odot}$, Luigi Maria Cavallo ${ }^{3 \odot}$, \\ Domenico Solari $^{3 \odot}$, Vincenzo Esposito ${ }^{4 \odot}$, Francesco Tomasello ${ }^{1 \odot}$, Paolo Cappabianca ${ }^{3 \odot}$ \\ 1 Department of Biomedical and Dental Sciences and Morpho-Functional Imaging, Division of Neurosurgery, \\ Università degli Studi di Messina, Messina, Italy, 2 Independent medical advisor, Cervignano del Friuli, Italy, \\ 3 Department of Neurosciences and Odontostomatological and Reproductive Sciences, Division of \\ Neurosurgery, Università degli Studi di Napoli Federico II, Naples, Italy, 4 Division of Neurosurgery, \\ Università degli Studi di Roma Sapienza, Rome, Italy \\ ๑ These authors contributed equally to this work. \\ * fesposito@unime.it
}

\section{Abstract}

\section{f openaccess}

Citation: Esposito F, Angileri FF, Kruse P, Cavallo LM, Solari D, Esposito V, et al. (2016) Fibrin Sealants in Dura Sealing: A Systematic Literature Review. PLOS ONE 11(4): e0151533. doi:10.1371/journal. pone. 0151533

Editor: Giovanni Grasso, Universita degli Studi di Palermo, ITALY

Received: October 28, 2015

Accepted: February 28, 2016

Published: April 27, 2016

Copyright: @ 2016 Esposito et al. This is an open access article distributed under the terms of the Creative Commons Attribution License, which permits unrestricted use, distribution, and reproduction in any medium, provided the original author and source are credited.

Data Availability Statement: All data are available in publications searchable through Cochrane Database of Systematic Reviews (http://www.cochrane.org/ cochrane-reviews), Cochrane Central Register of Controlled Trials, MEDLINE/PubMed (1950 to present [2015 June]), www.clinicaltrials.gov (searched for on-going trials or other concluded trials), and EMBASE via Ovid (1974 to present [2015 June]).

Funding: Dr. Felice Esposito received an unrestricted research grant from Baxter Italy and has given some didactic presentations on Dural Sealing methods. Dr. Paolo Cappabianca received an

\section{Background}

Fibrin sealants are widely used in neurosurgery to seal the suture line, provide watertight closure, and prevent cerebrospinal fluid leaks. The aim of this systematic review is to summarize the current efficacy and safety literature of fibrin sealants in dura sealing and the prevention/treatment of cerebrospinal fluid leaks.

\section{Methods}

A comprehensive electronic literature search was run in the following databases: Cochrane Database of Systematic Reviews, Cochrane Central Resister of Controlled Trials, clinicaltrials.gov, MEDLINE/PubMed, and EMBASE. Titles and abstracts of potential articles of interest were reviewed independently by 3 of the authors.

\section{Results}

A total of 1006 database records and additional records were identified. After screening for duplicates and relevance, a total of 78 articles were assessed by the investigators for eligibility. Thirty-eight were excluded and the full-text of 40 articles were included in the qualitative synthesis. Seven of these included only safety data and were included in the safety assessment. The remaining 33 articles included findings from 32 studies that enrolled a total of 2935 patients who were exposed to fibrin sealant. Among these 33 studies there were only 3 randomized controlled trials, with the remaining being prospective cohort analysis, case controlled studies, prospective or retrospective case series. One randomized controlled trial, with 89 patients exposed to fibrin sealant, found a greater rate of intraoperative watertight dura closure in the fibrin sealant group than the control group (92.1\% versus $38.0 \%, p<0.001$ ); however, post-operative cerebrospinal fluid leakage occurred in more fibrin sealant than control patients $(6.7 \%$ versus $2.0 \%, p>0.05)$. Other clinical trials evaluated the effect of fibrin sealant in the postoperative prevention of cerebrospinal fluid leaks. 
unrestricted research grant from Baxter Italy and has given some didactic presentations on Dural Sealing methods. Dr. Peter Kruse was paid for this structured literature review as an independent clinical consultant. The funders had no role in study design, data collection and analysis, decision to publish, or preparation of the manuscript.

Competing Interests: Dr. Felice Esposito received an unrestricted research grant from Baxter Italy and has given some didactic presentations on Dural Sealing methods. He has no other conflicts of interest. Dr. Paolo Cappabianca received an unrestricted research grant from Baxter Italy and has given some didactic presentations on Dural Sealing methods. He has no other conflicts of interest. Dr. Peter Kruse was paid for this structured literature review as an independent clinical consultant. He has no other conflicts of interest. This does not alter the authors' adherence to PLOS One policies on sharing data and materials.
These were generally lower level evidence studies (ie, not prospective, randomized, controlled trials) that were not designed or powered to demonstrate a significant advantage to fibrin sealant use. Two small case series studies evaluated the effect of fibrin sealants in persistent cerebrospinal fluid leak treatment, but did not establish firm efficacy conclusions. Specific adverse reports where fibrin sealants were used for dura sealing were limited, with only 8 cases reported in neurosurgical procedures since 1987 and most reporting only a speculative relationship/association with fibrin sealant exposure.

\section{Conclusions}

A major finding of this systematic literature review is that there is a paucity of randomized studies that have evaluated the effectiveness and safety of fibrin sealants in providing intraoperative watertight dura closure and post-operative cerebrospinal fluid leakage. Among the limited studies available, evidence from a single randomized, controlled trial indicates that fibrin sealants provide a higher rate of intraoperative watertight closure of the dura suture line than control, albeit with a higher rate of postoperative cerebrospinal fluid leakage. Evidence from non-randomized, controlled trials suggests that fibrin sealants may be effective in preventing cerebrospinal fluid leaks with an acceptable safety profile. There is a substantial need for randomized, controlled clinical trials or well-designed prospective observational trials where the conduct of a randomized trial is not feasible to fully assess the impact of fibrin sealant utilization on the rates of intraoperative dura closure, postoperative cerebrospinal leakage, and safety.

\section{Introduction}

In neurosurgery, disruption of the arachnoid and dura allows cerebrospinal fluid (CSF) to flow or leak into an extradural space-an event that may lead to life-threatening complications such as infection and pneumocephalus. Reported incidences of CSF leaks vary from $0.8 \%$ to $13 \%$ depending on type of surgery and other factors [1-4]. The relative risk of developing meningitis in patients with postoperative CSF leak has been reported to be more than 10 [5].

Neurosurgeons aim to reduce the risk of CSF leaks by meticulous suturing of the dura, fibrin sealants, and by the use of dural patches/grafts when possible. In other cases, such as endonasal endoscopic skull base surgery, primary suturing of the dura mater may be very difficult or even impossible to achieve [6-11]. With increased intracranial pressure $(>20 \mathrm{~cm} \mathrm{H} 2 \mathrm{O})$, CSF may leak through even small suture holes causing a persistent CSF leak. To minimize the risk of such CSF leaks, new approaches have been applied to provide a watertight closure of the dural incision/lesion; one such treatment modality is to use a fibrin sealant (FS) directly on the suture line to seal the suture holes.

Fibrin sealants are commercially available products that contain two main active ingredients, fibrinogen and thrombin (human/animal/recombinant origin), that when mixed form a fibrin clot [12]. These products are used to seal biological tissues, either as two component (ie, fibrinogen and thrombin) liquid glue or as a two component dry patch. Liquid glue formulations include Tisseel ${ }^{\circledR}$ or Tissucol ${ }^{\mathrm{m}}$ (Baxter, Deerfield, IL, USA), Evicel ${ }^{\circledR}$ (Ethicon US, LLC), and dry patch products such as Tachosil ${ }^{\mathbb{R}}$ (Baxter, Deerfield, IL, USA) and Tachocomb ${ }^{\mathbb{R}}$ (CSL Behring, Tokyo, Japan) [12]. Among these products, Tisseel / Tissucol is one of the first fibrin sealants and has been on the market over 30 years-it was first introduced to the European 
market in 1978. Tisseel has two main active component groups: 1) Human fibrinogen, synthetic aprotinin (anti fibrinolytic) and Factor XIII and 2) Human thrombin and calcium chloride [9]. When the two groups are mixed and applied to tissue, the fibrinogen and thrombin lead to generation of a fibrin clot that will adhere to tissue and have haemostatic (cease bleeding) and adhesive (seal and act as a bio glue) capacities [13].

The haemostatic effectiveness of using a fibrin sealant in surgery has been well established in a Cochrane review establishing its reduction of both postoperative blood loss and perioperative exposure to allogeneic red blood cell transfusion [14]. The non-blood compartment air tight and water tight sealing effects of fibrin sealants have been studied in randomized controlled trials of many types of surgery. These include sealing of intestinal anastomosis and preventing anastomotic leaks [12, 15-17], reduction of alveolar air leaks after pulmonary surgery [18], prevention of urethrocutaneous fistula after hypospadias repair [19], and in prevention of pancreatic fistula [20] although an earlier randomized trial did not report this same effect [21]. Fistulae sealing represents a therapeutic use of fibrin sealants with studies reporting fistulae closure in perianal/anal fistulaes [22, 23], complex anal fistulae [24, 25], and obstetrical vesicovaginal fistulaes [26].

In patients undergoing neurosurgical procedures, fibrin sealant properties of tissue adhesion, sealing, and bioabsorption potentially provide logical and clinically relevant benefits in where there is a need for effective dura mater sealing, prevention of perioperative acute CSF leakage, and/or treatment of persistent postoperative CSF leakage. The aim of this systematic review is to evaluate and summarize the current dura sealing efficacy and safety literature of fibrin sealants. This information will provide guidance as to whether the clinical efficacy and safety data for fibrin sealants support their use in dura sealing, either to prevent acute CSF perioperative leaks in patients following neurosurgery or to prevent/treat persistent CSF postoperative/post-instrumentation leaks in patients undergoing neurologic or spinal procedures.

\section{Methods}

\section{Search Strategy}

PRISMA recommendations and criteria for a structured literature search and review were followed [27]. An extensive systematic literature search was performed by an independent clinician (PK) of the following electronic databases: Cochrane Database of Systematic Reviews (http://www.cochrane.org/cochrane-reviews), Cochrane Central Register of Controlled Trials, MEDLINE/PubMed (1950 to present [2014 May]), www.clinicaltrials.gov (searched for ongoing trials or other concluded trials), and EMBASE via Ovid (1974 to present [2014 May]).

For the MEDLINE and EMBASE searches, a wide variety of Medical Subject Headings $(\mathrm{MeSH})$ have been used in key papers, therefore, exploded MeSH terms were used to ensure that all the appropriate papers were captured. The main search terms used to capture all the studies available in MEDLINE and EMBASE are summarized in Table 1. The Cochrane Library was searched using the search terms "fibrin sealant" or "cerebrospinal fluid." For the www. clinicaltrials.gov search, the broad search terms of "dura", "fibrin sealant", or "CSF leak" were used to identify completed or ongoing clinical trials evaluating the use of fibrin sealants in dura sealing.

\section{Article Eligibility and Selection}

Two physicians (FE and PK) scanned independently the retrieved articles' titles and abstracts for potential relevance and review inclusion eligibility. To be included, the article had to meet strict criteria, as listed in Table 2, with the search and inclusion criteria primarily targeting published studies or case reports presenting clinical efficacy and/or safety types of evaluations of 
Table 1. Search Strategy for the MEDLINE/PubMed Database.

\begin{tabular}{|c|c|}
\hline Number & Searches \\
\hline \multicolumn{2}{|c|}{$\frac{\text { Identification of procedures and treatment target }}{\text { (CSF leak): }}$} \\
\hline 1 & Neurosurgical Procedures [MeSH] \\
\hline 2 & Neurosurgery [MeSH] \\
\hline 3 & Cerebrospinal Fluid [MeSH] \\
\hline 4 & Cerebrospinal fluid leak [MeSH] \\
\hline 5 & cerebrospinal \\
\hline 6 & cerebrospinal fluid \\
\hline 7 & cerebrospinal fluid leak \\
\hline 8 & dura mater \\
\hline 9 & spinal puncture \\
\hline 10 & spinal tap \\
\hline 11 & $\begin{array}{l}\# 1 \text { OR \#2 OR \#3 OR \#4 OR \#5 OR \#6 OR \#7 OR \#8 } \\
\text { OR \#9 OR \#10 }\end{array}$ \\
\hline \multicolumn{2}{|c|}{ Identification of relevant fibrin sealants: } \\
\hline 12 & Fibrin Tissue Adhesive [MeSH] \\
\hline 13 & fibrin adhesive \\
\hline 14 & fibrin glue \\
\hline 15 & fibrin seal \\
\hline 16 & biological glue \\
\hline 17 & biological seal \\
\hline 18 & beriplast \\
\hline 19 & biocol \\
\hline 20 & collaseal \\
\hline 21 & crosseal \\
\hline 22 & evicel \\
\hline 23 & hemaseal \\
\hline 24 & omrixil \\
\hline 25 & quixil \\
\hline 26 & tachocomb \\
\hline 27 & tachosil \\
\hline 28 & tisseel \\
\hline 29 & tissel \\
\hline 30 & tissucol \\
\hline 31 & transglutine \\
\hline 32 & vivostat \\
\hline 33 & \#12 OR \#13 OR. .......\#32 \\
\hline \multicolumn{2}{|c|}{ Filter identification } \\
\hline 34 & animals [mh] NOT humans [mh] Final search \\
\hline 35 & \#11 AND \#33 NOT \#34 \\
\hline
\end{tabular}

doi:10.1371/journal.pone.0151533.t001

fibrin sealants used intraoperatively during neurosurgical procedures to prevent and/or treat CSF leaks. If only a few or no randomized controlled trials were identified, lower evidence level reports (as defined in Table 3 [28]) were allowed for an evaluation of efficacy provided that the scope of the research was to evaluate the effect of fibrin sealants in dura sealing. The results of the two independent searches were matched in order to find the common results; the two physicians reviewed the unmatched findings once more, in order to check if they met the inclusion 
Table 2. Article Inclusion and Exclusion Criteria.

\begin{tabular}{ll}
\hline Inclusion Criteria \\
\hline Types of Studies & $\begin{array}{l}\text { Randomized controlled trials evaluating the efficacy of fibrin } \\
\text { sealants in dura sealing. Non-randomized, controlled trials reporting } \\
\text { efficacy were allowed provided that the scope of the research was } \\
\text { to evaluate the effect of fibrin sealants in dura sealing. }\end{array}$ \\
& $\begin{array}{l}\text { All evidence levels, including case reports, that including safety data } \\
\text { were acceptable for safety analysis inclusion. }\end{array}$
\end{tabular}
were acceptable for safety analysis inclusion.

Types of Participants

Patients (irrespective of age, sex or race) who: a) had undergone neurosurgical intervention of the brain or spine where fibrin sealants had been used to seal dura in order to treat acute CSF leaks and/or to prevent CSF leaks

or presented with persistent CSF leaks after neurosurgical procedures where conservative treatment had failed and where attempts to close the CSF leak using fibrin sealants had been done or had spinal tap procedures with persistent CSF leaks.

Types of Interventions

Types of comparators

Placebo (sham) or no fibrin sealant treatment (just sutures).

Medical treatment with acetazolamide.

Conservative treatment with persisting CSF leak

Types of Efficacy Outcome Measures

Could include (but not limited to): 1. After Surgery: a) acute CSF leaks (preferably after Valsalva maneuver to increase intracranial pressure); b) Early (1 week) persistent CSF leaks ( $\beta 2$-transferrin, computed tomography or magnetic resonance imaging); or $\mathrm{c}$ ) Late ( $>4$ weeks) persistent CSF leaks ( $\beta 2$-transferrin, computed tomography or magnetic resonance imaging).

2. After CSF Leak: a) the number of patients with effective closure of the CSF leak

Safety Outcome

Measures

Could include (but not limited to):

Mortality

Overall incidence of serious adverse events (quantitative).

Overall incidence of adverse events related to fibrin sealants

(quantitative).

Qualitative assessment of specific adverse events/serious adverse

events related to use of fibrin sealants.

Reoperation rate due to CSF leaks.

\section{Exclusion Criteria}

Minor case series/case reports with $<20$ patients.

Case series where different surgical techniques (including technical notes) are compared rather than the potential effects of fibrin sealants.

Cost data reports without efficacy or safety data

Reviews, editorials, opinions, comments, and letters without original data.

Non-clinical (ie, experimental, animal, or in vitro) studies.

Clinical trials with major quality issues and a high risk of bias were excluded from efficacy analysis, but could be included in safety analyses.

Patients with spontaneous or trauma-related CSF leaks.

Patients where fibrin sealant was used for haemostatic effect only.

Fibrin sealants mixed with other products such as bone chips/powder, hydroxyapatite etc.

Comparisons of different fibrin sealant application methods.

Interventions where fibrin sealant is not applied on or close to dura/dura grafts or suture lines involving dura to provide dura sealing.

Reports on the sole use of autologous/homemade fibrin sealants (non-standardized product characteristics).

Studies where different patches/dura substitutes are compared and fibrin sealants are used as the standard of care.

doi:10.1371/journal.pone.0151533.t002 
Table 3. Defined Levels of Evidence in Literature Search Articles.

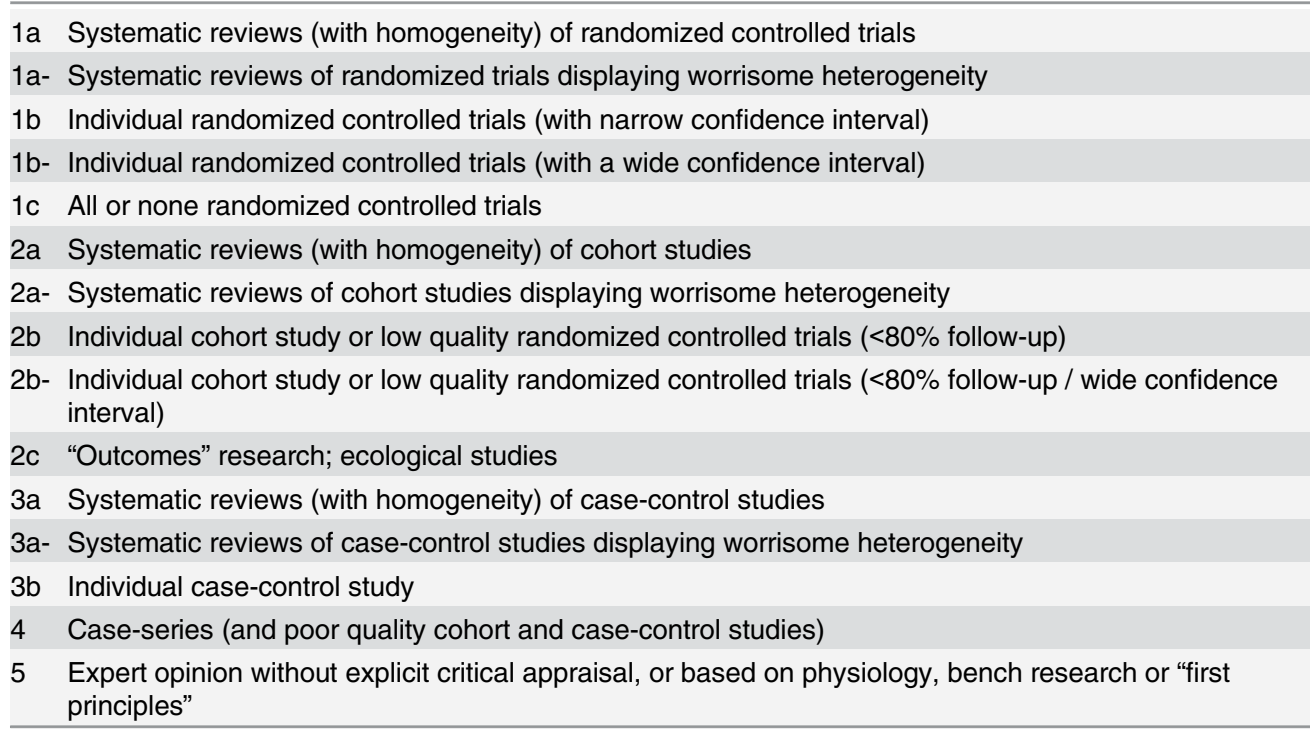

Based on data from the Oxford Centre for Evidence-based Medicine [28], which is available at: http://www. cebm.net/index.aspx?0=1025

doi:10.1371/journal.pone.0151533.t003

eligibility criteria. No cases of further disagreement between the two searching physicians occurred. Should any disagreement occurred, the relative articles would have been omitted from the analysis.

Among the identified articles meeting the selection criteria, full versions were used for data analysis and a secondary search of the listed citations was performed to ensure that all relevant publications were included. English-language publications were the primary focus, although studies in Italian and German were also assessed for potential importance/relevance with those reporting adverse events being translated (if the English abstract was not sufficient or available) and included in the safety analysis.

\section{Data Appraisal and Extraction}

The following data were extracted from each identified publication: trial characteristics including its design and outcome measures, setting, location of care, and country; participant descriptions including sample size, age, sex, disease, and surgical procedure; intervention information including the type and brand of fibrin sealant used and, if comparator used, the type and brand; and details of study efficacy and/or safety results.

\section{Results}

\section{Characteristics of Included Studies}

The MEDLINE/PubMed and EMBASE literature searches identified a total of 1004 potential citations with 3 citations identified through the www.clinicaltrials.gov search: no citations were identified through the search of the Cochrane Library. Of the 3 citations identified through the clinicaltrials.gov site at the time of the literature review, results were posted for one study (NCT00681824 [29]), one study was listed as completed without posted results (NCT01355627 [30]); and a citation (NCT01174992 [31]) with results found in a European Medicines Agency 


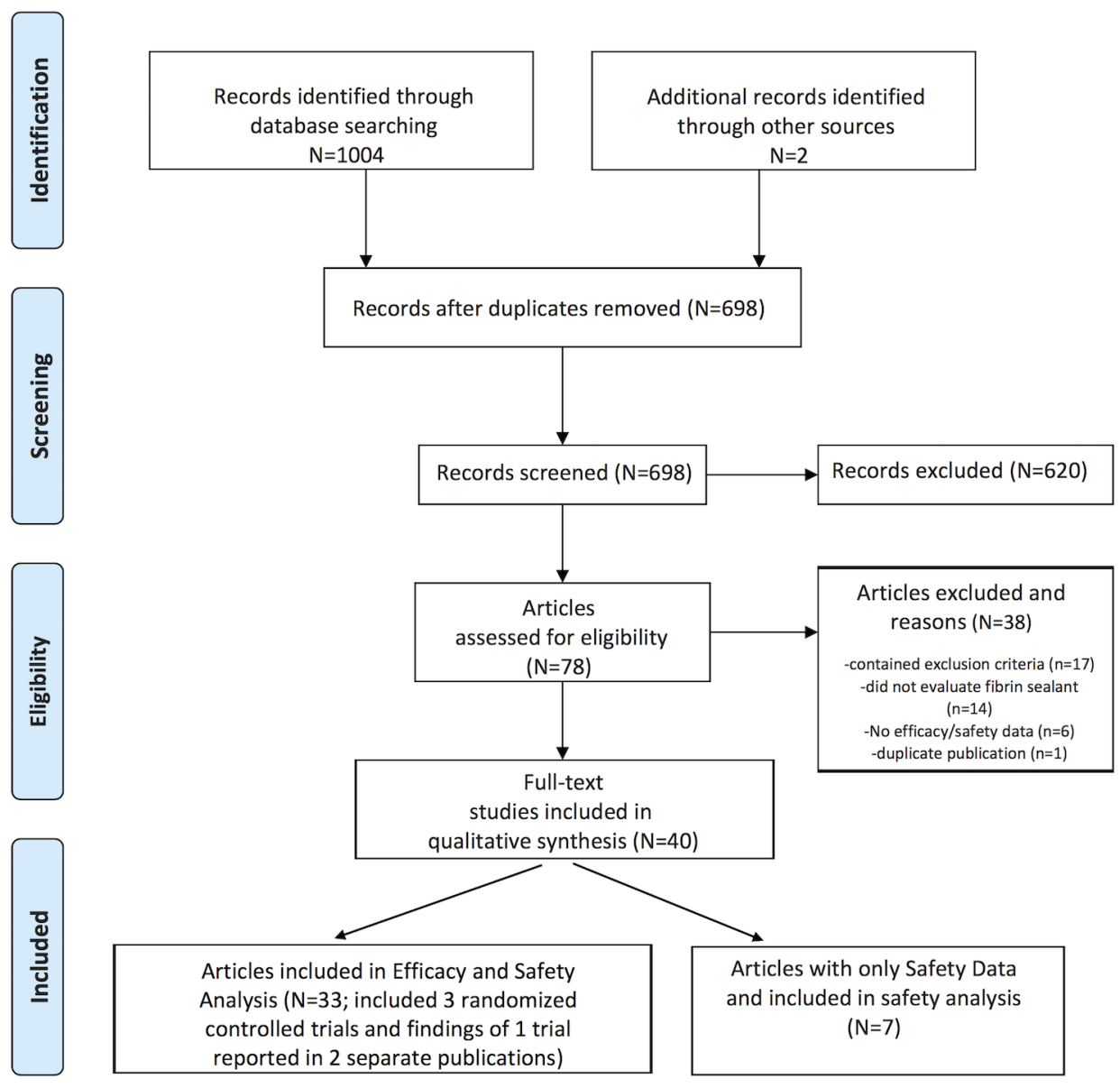

Fig 1. PRISMA Flow Diagram of the Selection Process to Identify Studies for Review.

doi:10.1371/journal.pone.0151533.g001

report [24]. The flow chart of the literature search and the citation selection, review, and inclusion and exclusion process are illustrated in Fig 1.

After the application of methods to remove 309 duplicate references (Reference Manager Profession, Version 12, Thomson Reuters and manual screening), a total of 697 citations remained. The abstracts of these citations were screened for inclusion and exclusion criteria and relevance, with 620 of these excluded as they did not cover the subject of the literature review. The full-text of the remaining 78 papers were reviewed and, of these, 40 met the a priori defined selection criteria with 33 meeting that for efficacy and some of these reporting on safety. Two of the 33 papers reported on patients enrolled in a single trial $[10,11]$. Seven papers contained specific safety reporting on fibrin sealant use in the predefined indication of neurosurgery for dura sealing. The citations were evaluated for their levels of evidence (Table 4) [28]. Three of the studies were randomized controlled trials of evidence levels $1 b$ to $2[24,29,32]$ with the remaining being retrospective case series or cohort studies of evidence levels $2 \mathrm{~b}$ to 4 .

Among the reviewed citations, a total of 2935 participants were exposed to fibrin sealants. Details of the study designs and participants, interventions, comparisons, outcome measures, and authors' conclusions are summarized for each trial in Table 5. By study type, 249 participants were exposed to liquid fibrin sealants in 2 of the 3 randomized controlled trials [24, 29]. A total of 126 participants were exposed to fibrin sealants in the remaining randomized controlled trial [32] and one prospective cohort study [33]. In 2 case controlled studies [34, 35], 
Table 4. Literature Search: Summary of Levels of Evidence of the Included Studies.

\begin{tabular}{|c|c|c|c|c|}
\hline $\begin{array}{c}\text { Level of } \\
\text { evidence [28] }\end{array}$ & Trial type & $\begin{array}{l}\text { Originally selected } \\
\text { studies }\end{array}$ & $\begin{array}{l}\text { Studies } \\
\text { included }\end{array}$ & $\begin{array}{c}\text { Total number of patients in studies } \\
\text { exposed to fibrin sealant }\end{array}$ \\
\hline$I$ & Meta-analysis & 0 & 0 & 0 \\
\hline lb-lb- & Randomized controlled trial & 2 & 2 & 123 \\
\hline II & $\begin{array}{l}\text { Prospective cohort studies / randomized } \\
\text { controlled trial with quality issues }\end{array}$ & 2 & 2 & 126 \\
\hline III & Case-control studies & 2 & 2 & 167 \\
\hline IV & Prospective and retrospective case series & 27 & 26 & 2519 \\
\hline Total & - & $33^{*}$ & $32 *$ & 2935 \\
\hline
\end{tabular}

Note: multiple publications addressing data from the same study are counted once:

*The total of included studies for efficacy and safety is 32 , two studies are reporting on the same patients [10, 11].

doi:10.1371/journal.pone.0151533.t004

167 participants were exposed fibrin sealants, with the remaining 25 case series analyses reporting on the remaining 2393 participants.

Notably, one case series citation by Cappabianca and colleagues of 50 subjects exposed to fibrin sealant, 40 were evaluated for postoperative CSF leak efficacy information: 10 subjects were evaluated for treatment of persisting CSF leak efficacy [42]. Although the 10 subject evaluation did not meet our literature search criteria, the information from this case series subpopulation was included for completeness [42].

\section{Fibrin Sealant Efficacy and Safety in Randomized Controlled Trials}

As detailed in Table 6, the quality of each of the 3 randomized controlled trials [24, 29, 32] varied in their level of evidence. The largest trial by Green and colleagues was conducted under the regulatory requirements for obtaining an indication in the European Union and was presented with an overall high study quality [24]. The remaining 2 randomized controlled trials had small numbers of participants [29, 32]. The one trial posted on clinicaltrials.gov (NCT00681824 [29]), a pilot study to investigate the efficacy and safety of fibrin sealant (Tisseel) for use in posterior fossa surgery as an adjunct to dura and dura substitute sutures in preventing postoperative CSF leakage, was performed without any formal sample size calculation. Limitations to the trial by Nakamura and colleagues [32] include its limited number of spinal patients with an a priori sample size calculation and use of a pseudo randomization (clinical chart number system), which may have resulted in the trial being underpowered and having bias. These design and power limitations limit the ability to draw conclusions of efficacy from their findings [32].

\section{Efficacy and Safety of Fibrin Sealants, by Indication}

The following subsections describe the strength of the overall evidence for the efficacy and safety of fibrin sealants in the prevention and/or treatment of acute or persistent CSF leaks, by these indications.

Treatment of acute (intraoperative) CSF leaks. One of the 3 randomized controlled trials was designed to evaluate the efficacy and safety of a liquid fibrin sealant containing both thrombin and fibrinogen as an adjunct to dura sutures in patients undergoing elective cranial surgery (supratentorial/posterior fossa) who experienced a CSF leak after primary suture closure of the dura mater [24]. This clinical trial [24], which was identified from the clinicaltrials. gov website, was used to submit data to the European Medicines Agency (EMA) to obtain the 


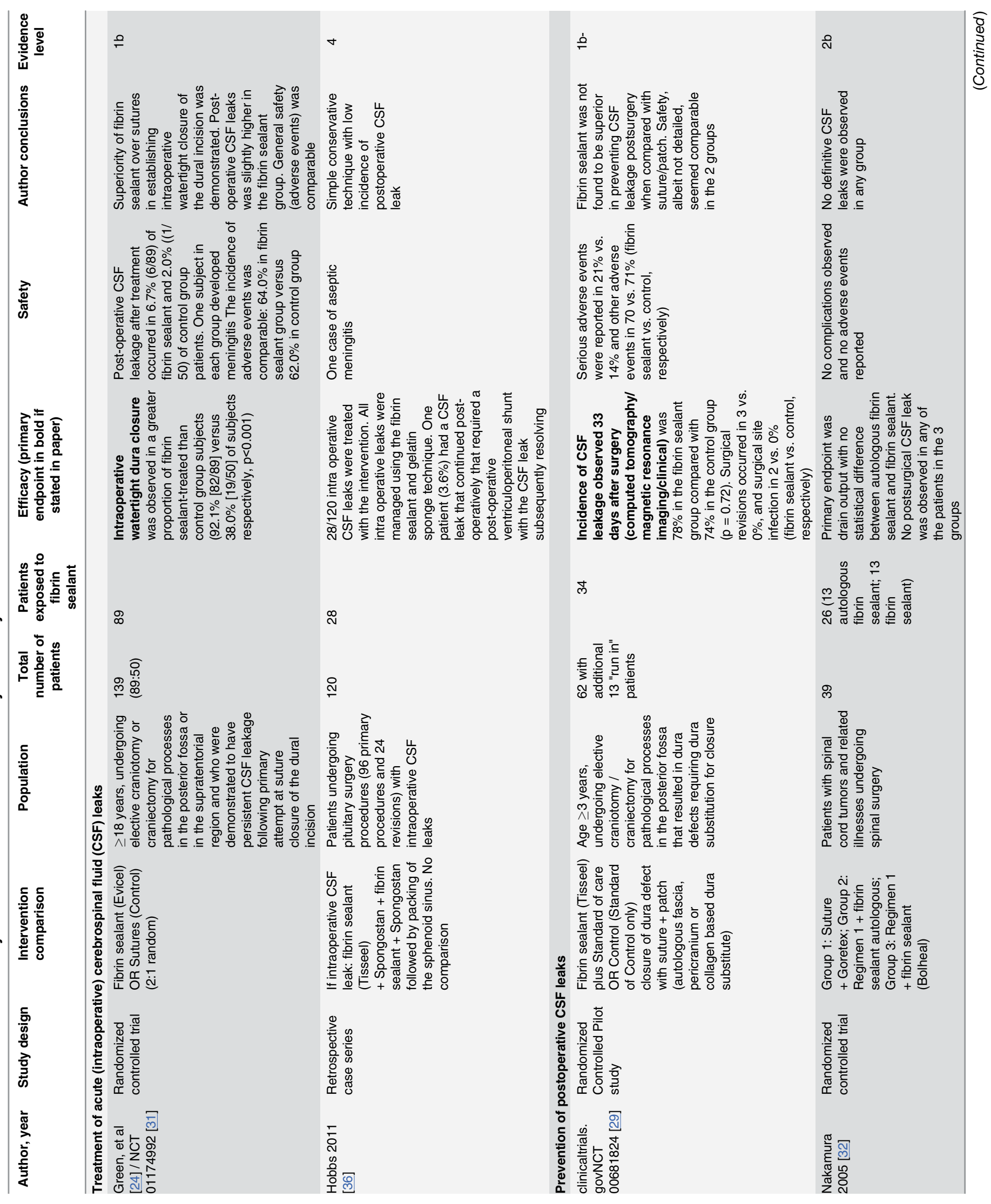




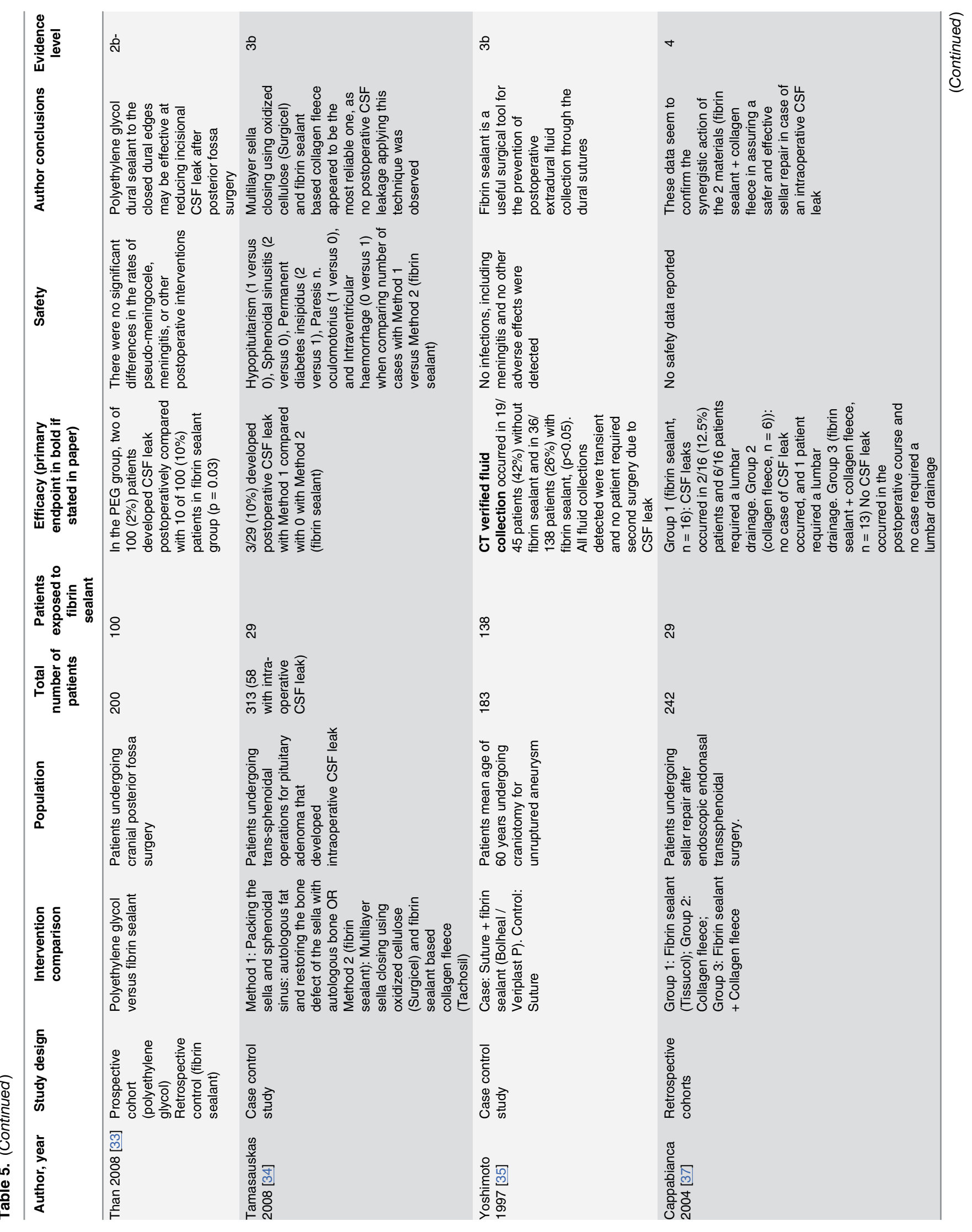




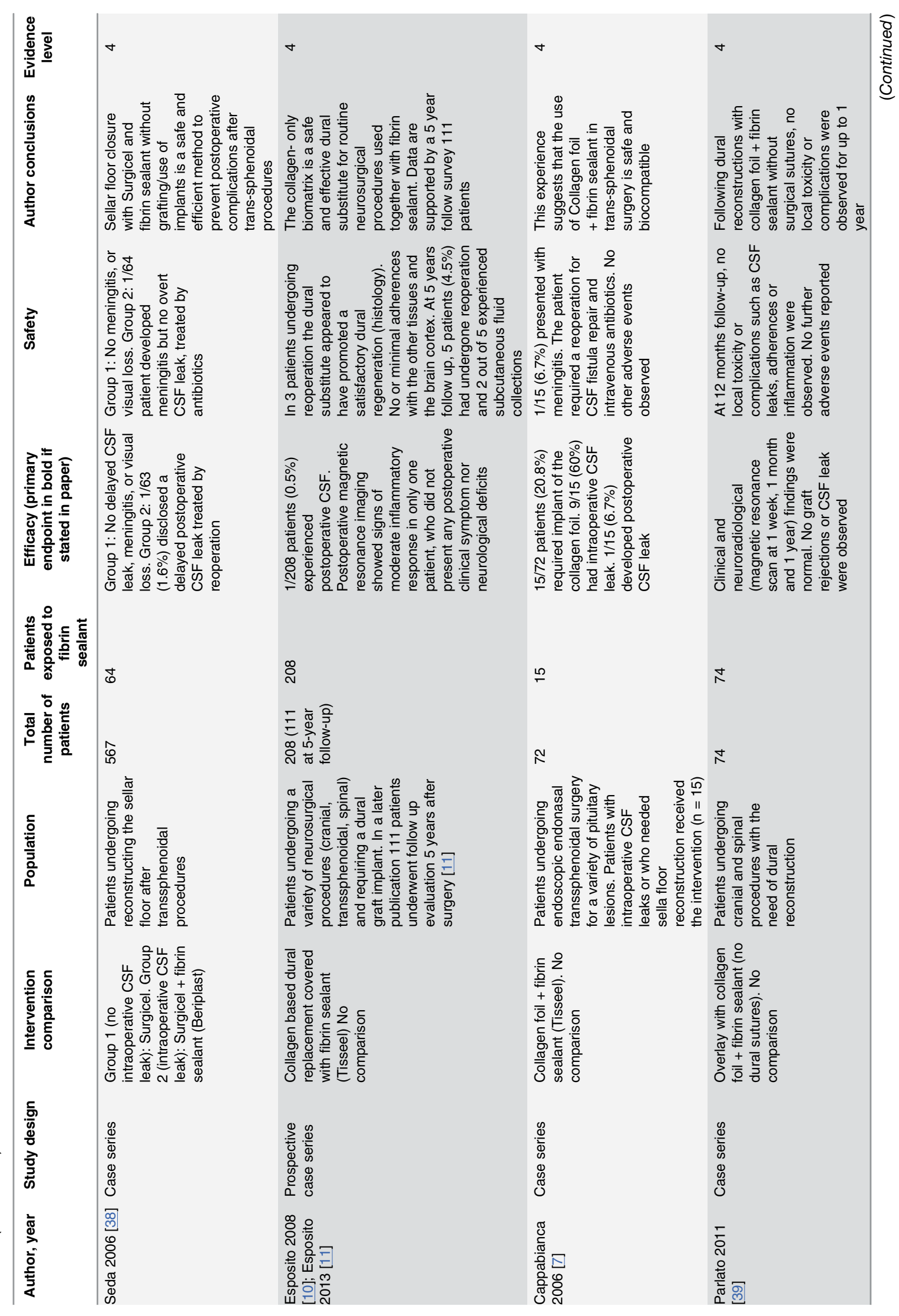




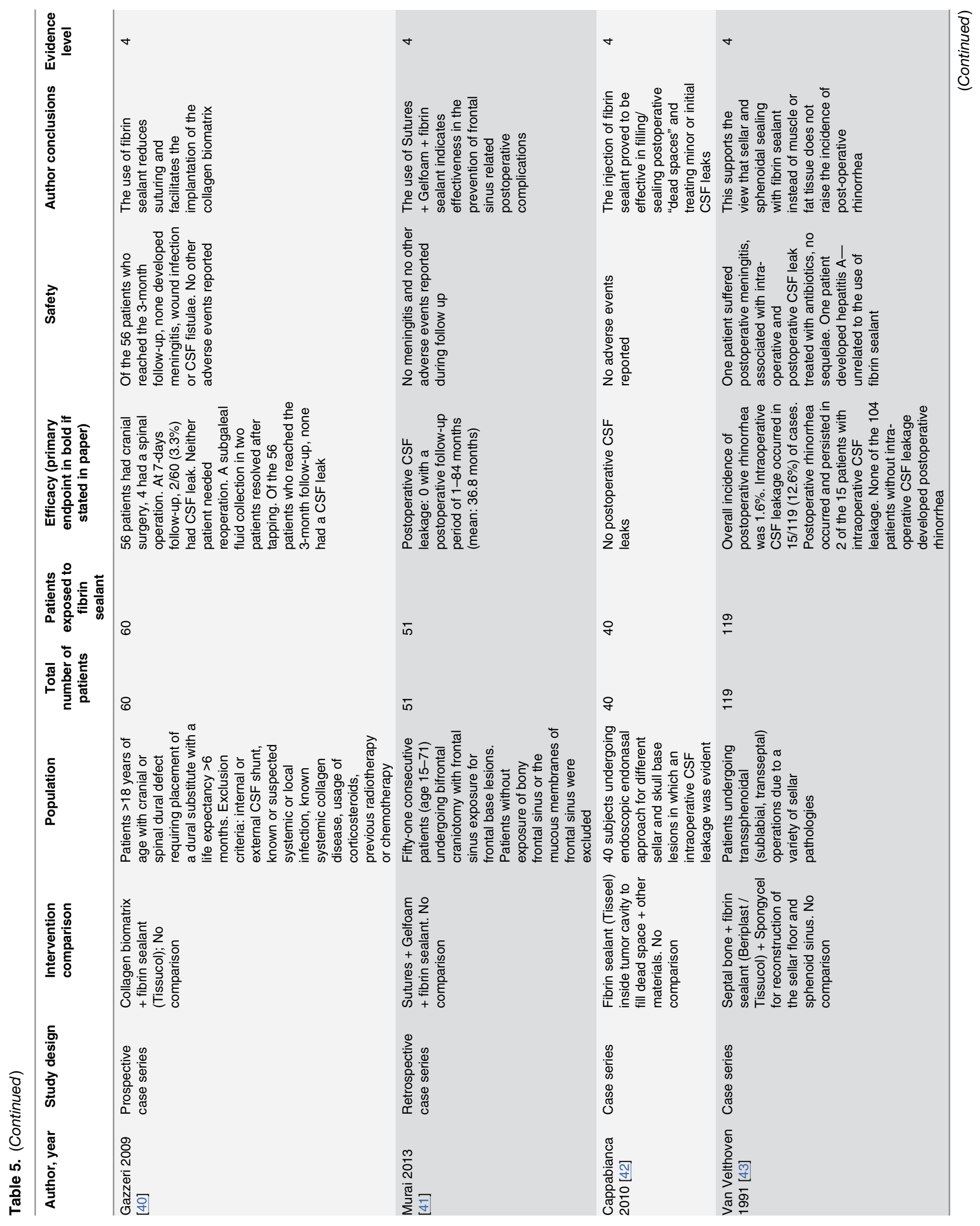




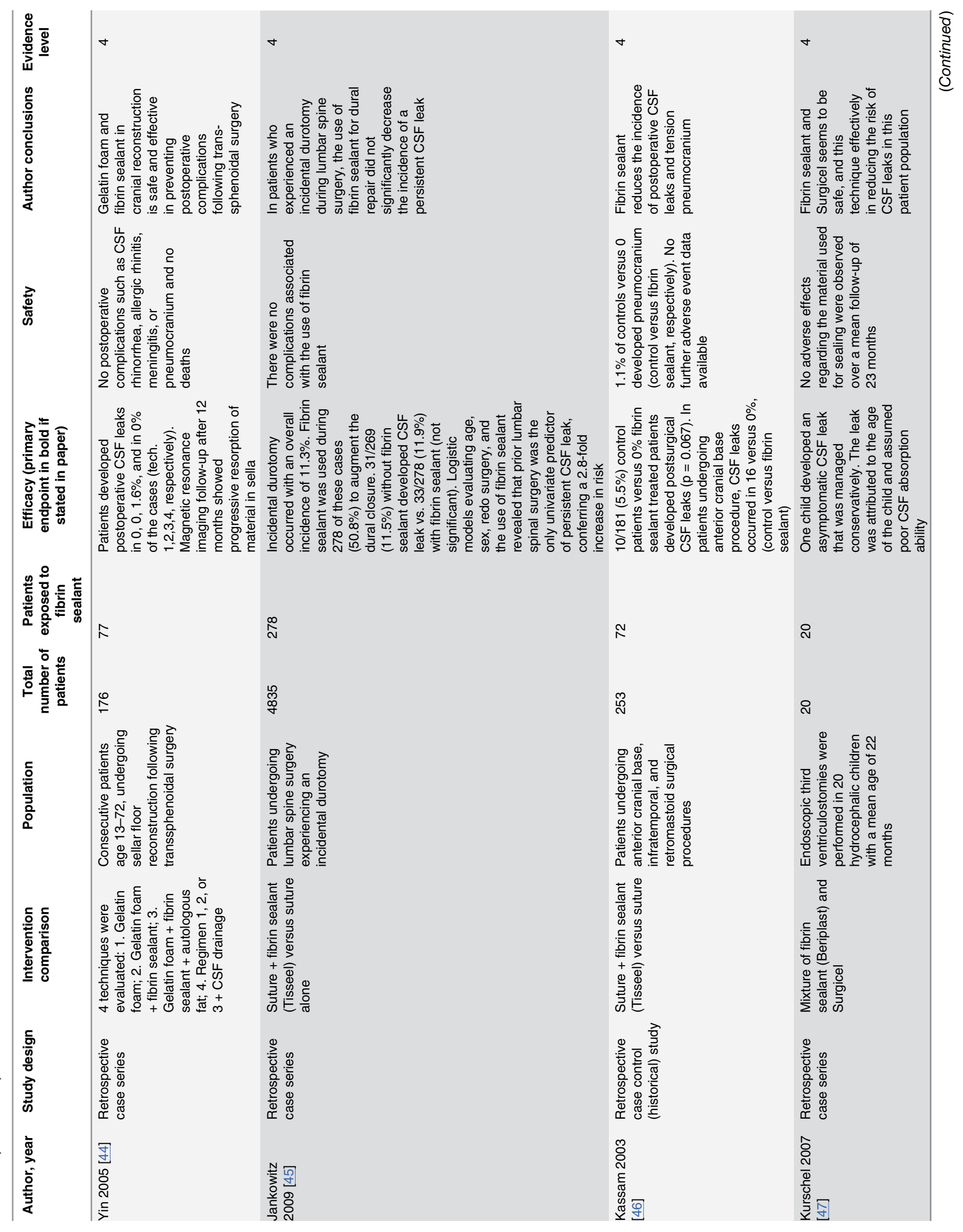




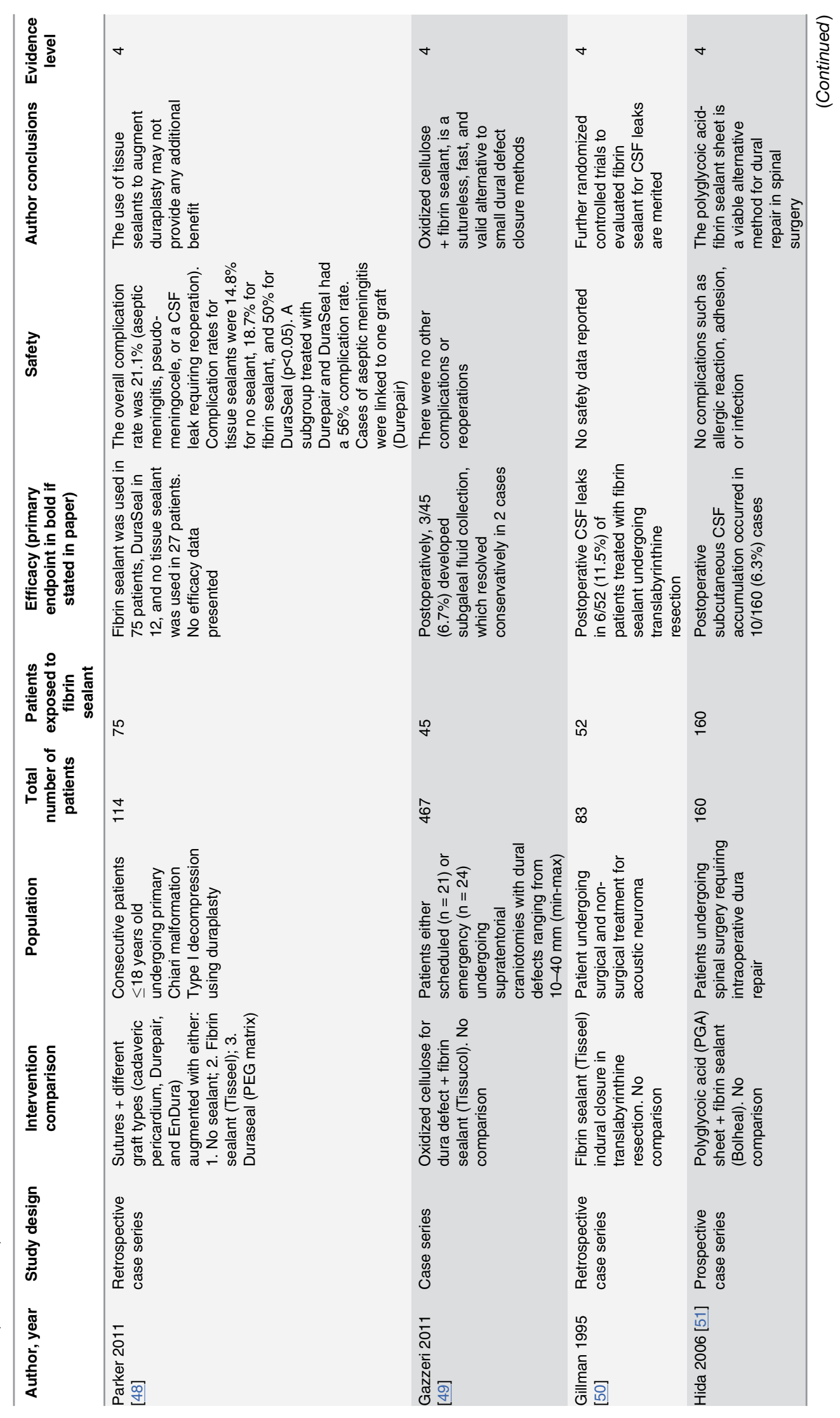




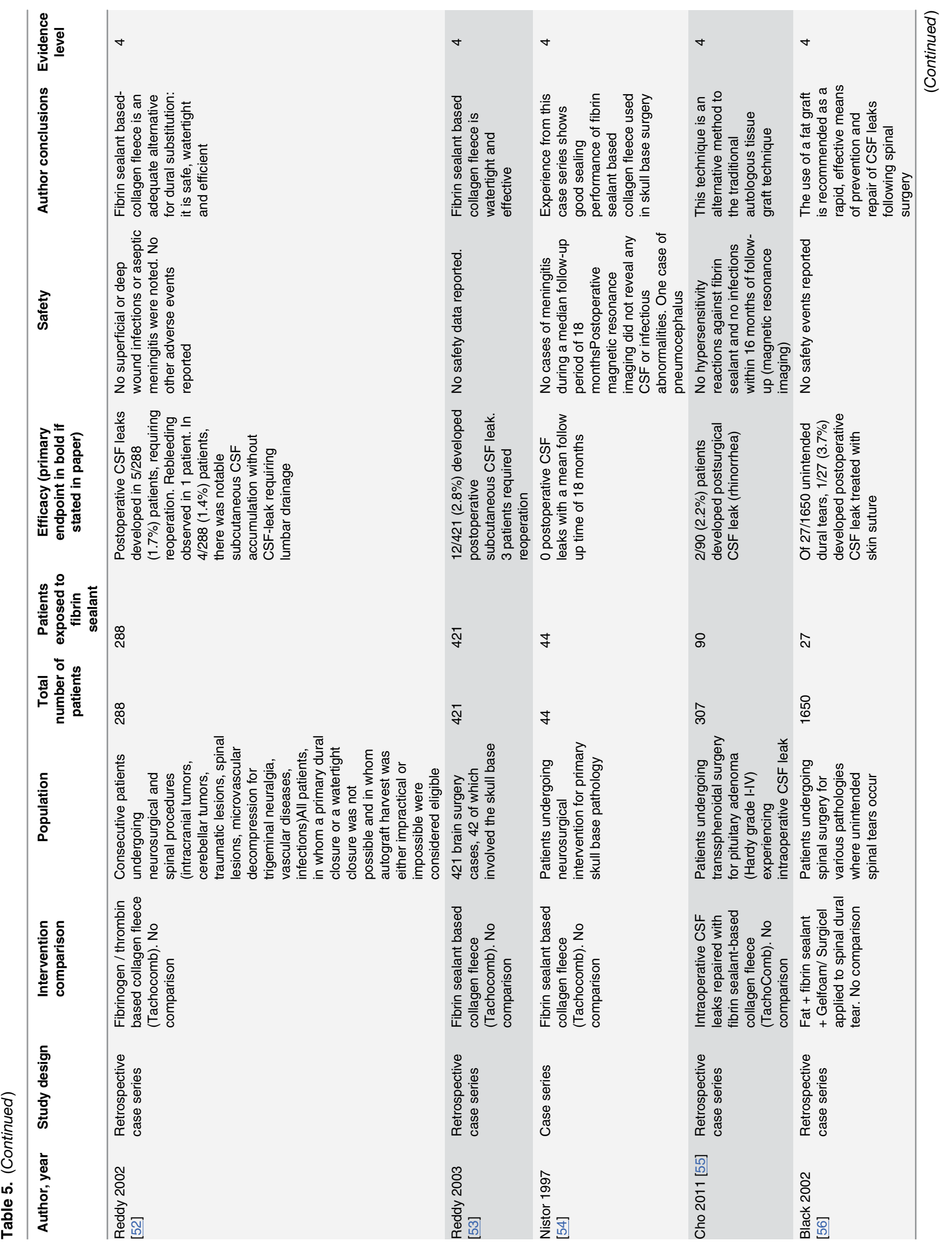




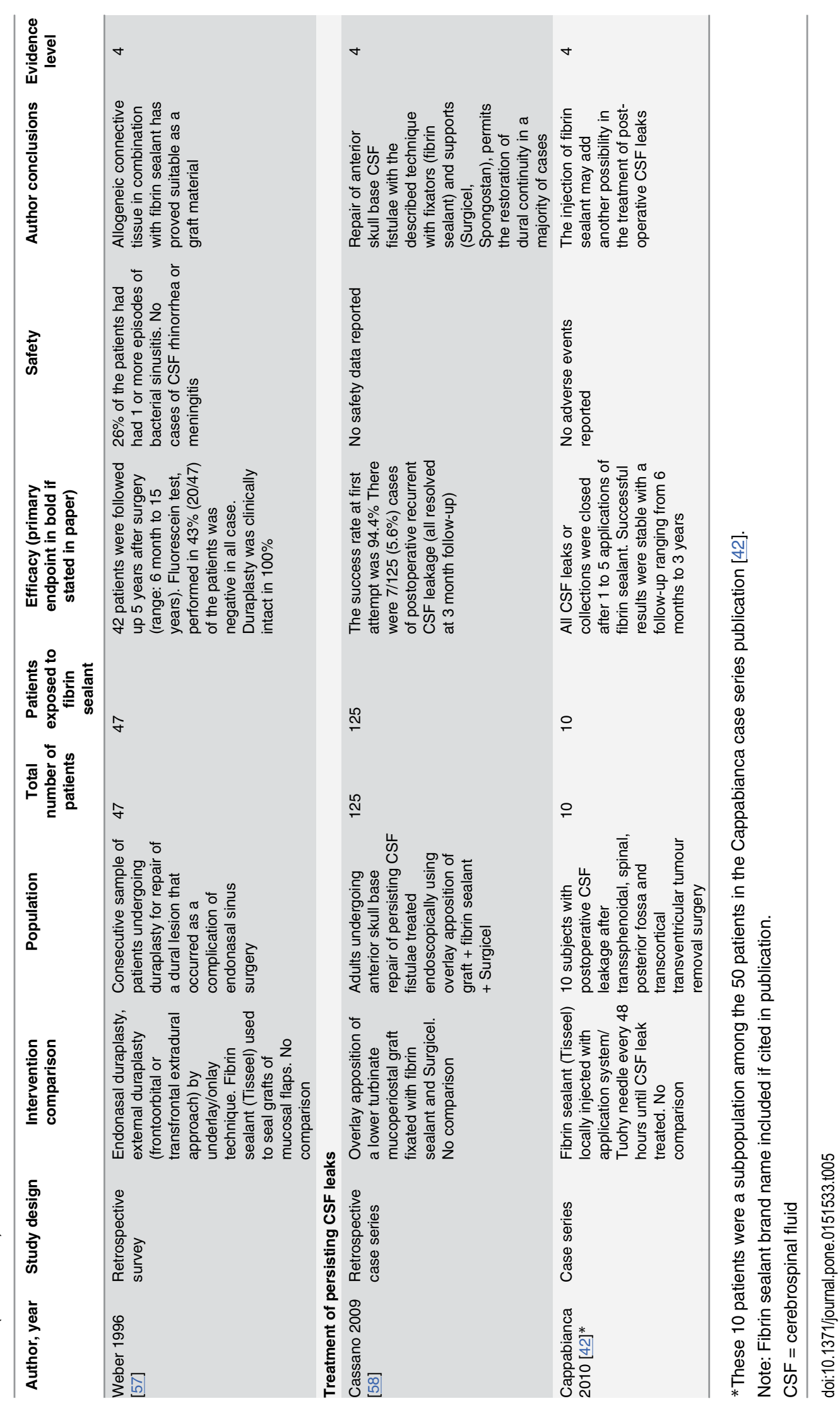


Table 6. Appraisal of Study Quality for Three Randomized Controlled Trials*.

\begin{tabular}{|c|c|c|c|c|c|c|c|c|c|c|}
\hline Study & $\begin{array}{c}\text { Primary } \\
\text { outcome } \\
\text { stated? }\end{array}$ & $\begin{array}{l}\text { Inclusion / } \\
\text { exclusion } \\
\text { specified }\end{array}$ & $\begin{array}{c}{ }^{\dagger} \text { Generation of } \\
\text { allocation } \\
\text { sequence } \\
\text { adequate? }\end{array}$ & $\begin{array}{l}{ }^{\dagger} \text { Allocation } \\
\text { concealment } \\
\text { adequate? }\end{array}$ & $\begin{array}{c}\text { a priori } \\
\text { sample size/ } \\
\text { power } \\
\text { calculation }\end{array}$ & $\begin{array}{c}\text { Blinded } \\
\text { outcome } \\
\text { assessors? }\end{array}$ & $\begin{array}{l}\text { Blinded } \\
\text { patients? }\end{array}$ & $\begin{array}{l}\text { Consecutive } \\
\text { cases? }\end{array}$ & $\begin{array}{l}\text { Intent-to- } \\
\text { treat } \\
\text { analysis }\end{array}$ & $\begin{array}{l}\text { Lost to } \\
\text { follow } \\
\text { up (\%) }\end{array}$ \\
\hline $\begin{array}{c}\text { Green } 2014 \\
{[24]}\end{array}$ & Yes & Yes & Unclear & Unclear & Yes & No & Yes & Yes & Yes & $(1-2 \%)$ \\
\hline $\begin{array}{c}\text { Clinicaltrials. } \\
\text { gov NCT } \\
\text { 00681824 } \\
\text { [29] }\end{array}$ & Yes & Yes & Unclear & Unclear & No & Yes & Yes & Yes & Yes & 0 \\
\hline $\begin{array}{c}\text { Nakamura } \\
2005 \text { [32] }\end{array}$ & Yes & Yes & No & No & Yes $^{\# 1}$ & No & Unclear & Yes & No & 0 \\
\hline
\end{tabular}

Possible answers for each section are: Yes (low risk of bias [ROB]), No (high ROB) and Unclear (Uncertain ROB).

Unclear denotes where there is insufficient information in the publication to permit a clear judgment).

ITT = intent to treat.

*Inspired by the risk of bias table (Figure 8.6.a) in Higgins JPT, Altman DG (Eds). Chapter 8: Assessing risk of bias in included studies. In: Higgins JPT, Green S (Eds). Cochrane Handbook for Systematic Reviews of Interventions. The Cochrane Collaboration, 2008. Availablwww.cochrane-handbook.org [59].

†The minimum criteria for adequate concealment are based on data from Schultz and Grimes, 2002 [60].

\#1: Sample size done, reported but not followed in actual study.

doi:10.1371/journal.pone.0151533.t006 
surgical revisions and infections, were distributed evenly in the two groups. The findings of this trial do not establish the prevention of CSF leaks with fibrin sealants, but did report a comparable safety profile between the sutures and patches standard of care and the use of fibrin sealant as an adjunct.

A smaller (39 patients) randomized controlled trial provided Evidence Level $2 \mathrm{~b}$ on the efficacy of liquid fibrin sealant adjunct to sutures and Goretex in the closure of spinal cord dura [32]. As mentioned previously, this study by Nakamura and colleagues had several designrelated quality issues that limit the interpretation of their findings such as use of a pseudo randomization system, an a priori sample size, and the potential for being underpowered and biased [32]. In the study, postoperative CSF leakage was the secondary endpoint with the primary endpoint being haemostasis. CSF leakage postoperatively was not observed in any of the study patients and no adverse events or complications were reported. Although not statistically significant, the data demonstrates that fibrin sealants were effective in preventing postoperative CSF leakage in the patients evaluated.

Three studies used a case control design [33-35] to assess fibrin sealants in preventing CSF leaks. In a study of 200 patients undergoing fossa posterior surgery with intraoperative CSF leaks, Than and colleagues [33] compared the use of fibrin sealants with PEG sealant. Overall, $10 \%$ of those exposed to fibrin sealants and $2 \%$ of those in the PEG group developed a postoperative CSF ( $p=0.03$ ). Yoshimoto and colleagues [35] compared treatment with a liquid fibrin sealant with sutures versus sutures alone (control group) in preventing postoperative CSF leaks in 183 patients undergoing craniotomy. The incidence of postoperative CSF leaks, verified by computed tomography, was $26 \%$ in the fibrin sealant group and $42 \%$ in the control group ( $p>0.05)$. Tamasauskas and colleagues [34] also used a case controlled approach to evaluate the incidence of postoperative CSF leaks in patients undergoing transsphenoidal surgery for pituitary adenoma with intraoperative detected CSF leaks. Intraoperative CSF leaks were treated with packing of the sella and sphenoidal sinus with different materials with a dry patch fibrin sealant or without (control group). No fibrin sealant-managed patient and $10 \%$ of those not managed with fibrin sealant developed a postoperative CSF leak. In these three case controlled trials [33-35], safety was reported to occur with a similar distribution between the fibrin sealant and control groups. In such trials where there is a high risk of bias that may influence the interpretation of efficacy and safety results, no consistency was shown of fibrin sealant efficacy and no safety issues were identified (Evidence level 3).

The majority of the selected papers reported data from case series that were either prospective or retrospective. In total, 22 such papers were selected with 2 papers reporting follow-up on same patient cohort $[10,11]$. In these analyses, fibrin sealants were used predominantly in cranial procedures $[10,11,39,40,41,46,48,49,52,54]$ with low incidences (0 to $6.7 \%)$ of postoperative CSF leaks reported. In one case series where fibrin sealant was used in a subgroup of patients undergoing surgical treatment for acoustic neuroma with translabyrinthine resection, $11.5 \%$ of patients experienced postoperative CSF leak [50]. Fibrin sealant was reported to be effective, with postoperative CSF leaks rates of 0 to $6.7 \%$, in patients undergoing transsphenoidal surgery $[7,37,38,42,43,44,55,57]$.

The use of fibrin sealant was assessed in 2 papers in patients undergoing transsphenoidal surgery. In the retrospective analysis by Cappabianca and colleagues [37], 2 of 16 patients (12.5\%) treated with fibrin sealant alone presented with a postoperative CSF leak compared to none of the patients who received a fibrin sealant/collagen fleece combination. In the consecutive patient analysis by Yin and colleagues [44], the 77 patients who developed a visible intraoperative CSF leak were repaired with fibrin glue plus gelatin foam $(n=62)$ or with autologous fat graft and sellar floor reconstruction $(n=15)$, with the authors concluding that the use of 
fibrin glue with gelatin foam was effective and safe in preventing postoperative complications following transsphenoidal surgery.

In a small case series of 20 children with hydrocephalus where fibrin sealant was used, one child (5\%)) developed a CSF leak [47]. In three case series of patients undergoing spinal surgery with dural repair where fibrin sealant was used to enforce the dural suture line, between 3.7\% to $11.9 \%$ of patients developed postoperative CSF leak $[45,51,56]$. In general, in these case series, safety events occurred infrequently (meningitis, pseudomeningocele, pneumocephalus, see Table 5 for details). The results from these case series are limited in their interpretation on safety and efficacy due to design (Evidence level 4).

In two retrospective case series an attempt was made to compare the effect of fibrin sealant to a control in the incidence of persistent CSF leakage [45, 48]. In the analysis by Jankowitz [45] of 547 patients undergoing lumbar surgery and experiencing incidental durotomy during the first 3-month postoperative period, a total of 64 patients (11.7\%) experienced a persistent CSF leak. There was no difference in the percentage of patients who experienced a persistent CSF leak in which fibrin glue was used to augment the dural closure $(11.9 \%, \mathrm{n}=33)$ and those in which fibrin glue was not used $(11.5 \%, \mathrm{n}=31)$ [45]. In a study by Parker and colleagues [48] of 114 consecutive children undergoing primary Chiari I malformation Type I decompression using duraplasty, the complication rate for tissue sealants was $14.8 \%$ in the 27 patients managed with no sealant and $18.7 \%$ for the 75 patients managed with fibrin sealant. The findings of these two studies $[45,48]$ indicate that there is no additional benefit of fibrin sealant use over other procedures; however, the retrospective case series design limits the ability to draw firm conclusions from these data.

Treatment of Persisting CSF leaks. Two case series reported the experience of treating patients with persisting CSF leaks after a variety of surgical intervention types (skull base, spinal, posterior fossa and other) [42, 58]. In the larger series of 125 patients by Cassano and colleagues [58], fibrin sealant used with turbinate grafts and Surgicel resulted in a postoperative recurrent CSF leakage rate of 5.6\%. In the smaller case series of 10 patients who underwent different neurosurgical procedures and developed postoperative CSF fistulas or collection, the local injection of fibrin sealant was effective in treating the complication [42]. Among the 10 patients, 4 had undergone transsphenoidal surgery, 2 had undergone spinal surgery, 3 underwent posterior fossa surgeries and one underwent transcortical transventricular tumour removal. In this study by Cappabianca 2010 and colleagues [42], the liquid fibrin sealant applications were repeated every 48 hours until the disappearance of the leak. The number of applications ranged from one to five, with the application being successful in all cases. No adverse events were reported in these studies. The results from these case series are limited in their interpretation on safety and efficacy due to the reported design (Evidence level 4).

Results for Safety Evaluation Based on Specific Reported Adverse Events. As summarized in Table 5, few or no adverse events were reported in most of the studies. In the three randomized controlled trials where there is a specific comparison of treatment with and without fibrin sealants [24, 29, 32], no increased adverse events due to fibrin sealants was detected (Table 5).

Table 7 presents an overview of specific adverse events reported in publications that reported on the safety of fibrin sealants used in or near dura mater. From 1987, when the first safety case was reported, until 2014 there have been a total of 8 cases in neurosurgery [61-67]. These 8 cases included 2 allergic reactions [61, 65], 3 cases of aseptic meningitis [66, 67], one case of meningitis with fatal outcome with only limited information provided in the paper [62], one case of suspected air embolism with the use of a spray device [63], and one case of obstruction of epidural drain [64]. One of the 2 allergic reactions was supported by the finding of serologic tests (specific IgE and IgG to the allergen) [61]. What is unknown is whether this 
Table 7. Literature Search: Specific Reported Adverse Events, in Alphabetical order by first author.

\begin{tabular}{|c|c|}
\hline Author, year & Report type \\
\hline $\begin{array}{l}\text { Beierlein, } \\
2000 \text { [61] }\end{array}$ & Case report \\
\hline $\begin{array}{l}\text { Czepko, } 2006 \\
\text { [62] }\end{array}$ & $\begin{array}{l}\text { Single case } \\
\text { report }\end{array}$ \\
\hline
\end{tabular}

Felema, 2013 Case report [63]

Handa, 1989 Case report [64]

Kanazawa, Case report 2010 [65]

Adverse event reported and incidence

48 year old woman developed a liquid fistula after cranial surgery for cerebral metastasis. 29 days postsurgery, $4 \mathrm{ml}$ fibrin sealant (Tissucol) was injected into subgaleal cavity. 40 days postsurgery another $4 \mathrm{ml}$ of fibrin sealant was injected followed by clinical signs of anaphylactic shock. Serology identified aprotinin specific lgE and IgG.

Limited information from abstract in English: 259 consecutive cases performed using a transsphenoidal approach. Intraoperative rhinorrhea occurred in 40 cases where fibrin sealant was used in sella reconstruction. Twenty-six (26) cases (group I) received Surgicel, artificial dura or fascia and fibrin sealant (Tissucol) and 14 cases (group II) received TachoComb + fibrin sealant, fascia or artificial dura. One patient died due to the meningitis (group I). No further information is available and no causality is given.

\section{A 5-month old, Ex-33-week premature, 6.6-kg male scheduled for} endoscopic cranial vault remodeling for sagittal craniosynostosis. At the completion of the surgical procedure and prior to skin closure, 4 $\mathrm{ml}$ of fibrin sealant (Tisseel) was applied for haemostasis at an approximate distance of $5 \mathrm{~cm}$ from the anterior endoscopic entrance site using an aerosolized spray applicator device (Easyspray) with nitrogen as a propellent gas at a pressure of $15 \mathrm{psi}$. Immediately after fibrin sealant delivery, a sudden drop in blood pressure from $88 / 42$ to $38 / 21$ was noted lasting $5 \mathrm{~min}$. with no perceived change in blood loss. It was hypothesized that air was introduced to the vascular system with the spray device.

In an observational study fibrin sealant (Beriplast B) was used in 48 places, at 36 neurosurgical operations in 34 patients. In one case where fibrin sealant was applied over the dural surface, obstruction of an epidural drain occurred resulting in an epidural haematoma (no further details in abstract).

A 65 year old woman underwent surgical craniotomy where arachnoid plasty with fibrin sealant (Beriplast) was completed. Nine days post-surgery the patient underwent abrupt neurological deterioration. Neuroimaging and clinical findings indicated allergic reaction that was successfully treated with steroids. It was hypothesized that components in the fibrin sealant led to the observed allergic reaction.

Schlenker, Controlled trial. This controlled trial evaluated fibrin sealant (Tissucol) for the 1987 [66] One case report prevention of post lumbar puncture headache. Following lumbar puncture, patients were treated with fibrin sealant injected through lumbar needle immediately after dural tap. The first 6 patients were treated uneventfully. The 7 th patient, a 58 year old female, developed aseptic meningitis treated with antibiotics. Allergy test for fibrin sealant components were negative. No evidence of contamination of trial product. The author suspected chemical irritation caused by component of the fibrin sealant could not be excluded.

Wakamoto, 2 Case reports $2002[67]$
Limited information from abstract in English: A 56 year old female undergoing microvascular decompression. Eighteen days after procedure the patient was diagnosed with aseptic meningitis. A 30 year old male experienced the same symptoms 15 days after same surgery. Dacron, Goretex and Lyodula were used together with fibrin sealant, the latter to prevent CSF leak. It was suggested that the human fibrinogen was the cause of the aseptic meningitis that was successfully treated with steroids.

\section{Comments}

Serology confirmed. Aprotinin is a bovine protein and as such is a potential allergen.

Very limited information and no causality to fibrin sealant given.

Causality to fibrin sealant only a hypothesis. Tisseel fibrin sealant has a special warning and precaution in Summary of Product Characteristics for use with gas and in confined spaces.

Spray directly on drain potential obstruction.

Causality to fibrin sealant only a hypothesis.

Causality to fibrin sealant only a hypothesis.

Causality to fibrin sealant only a hypothesis. 
allergic reaction would have been observed if the product was applied topically, rather than systemic. The second allergic reaction, like most reported reactions was not confirmed as directly related to the product, but could be possibly related [61].

When evaluating safety in these complex interventions and in patients with potential comorbidities, it is important to take into consideration the fact that a number of other products, including fibrin sealant, are used during these procedures. As such, direct determination of causality is difficult. Overall the specific adverse events are few and not frequently reported over a period of more than 25 years.

\section{Discussion}

Cerebrospinal fluid does not forgive and a careless dural closure almost certainly will result in a leak. For the surgeon, cerebrospinal fluid leaks are a frustrating complication of neurosurgical procedures, while for the patient these can result in unanticipated morbidity and mortality. Like most complications, cerebrospinal fluid leaks are best managed by prevention of their occurrence. During recent decades, dural closure after routine and emergency neurosurgical procedures has been performed with the use of suitable autologous, heterologous, or many different synthetic materials, and also with biological, semisynthetic, or synthetic glues. Such materials have been used individually or combined according to different techniques reported in the literature.

The introduction of fibrin sealants has resulted in the rate of postoperative CSF leakage being dramatically reduced thus reducing also the costs related to the management of CSF leak complications and the length of postoperative hospitalization. Fibrin sealants are widely used for a variety of neurosurgical indications such as dural closure and/or reinforcement

With this systematic literature review we aimed to evaluate the evidence available in the literature and relate it to our experience with fibrin sealants in neurosurgery. Our goal was to evaluate whether the clinical clinical data for fibrin sealants support their use in dura sealing, either to prevent acute CSF leaks (perioperatively) in patients after neurosurgery or to prevent/ treat persistent CSF leaks (postoperatively or with instrumentation) with regards to efficacy and safety of the products. This extensive literature search identified only a few randomized clinical trials that provide a high level of evidence regarding the efficacy and safety of fibrin sealants used for these indications. The literature search identified several lower quality studies including case series and reports that were included in our analysis, with these representing the majority of studies evaluated and a limitation to the conclusions that may be drawn from the findings.

In this systematic review the best quality study was a large randomized controlled trial that evaluated the perioperative application of fibrin sealants directly to the suture line to stop acute CSF leaks in patients undergoing neurosurgical procedures. The definition of a perioperative acute CSF leak is straightforward and simple and evaluated on the spot by the neurosurgeon. In the largest randomized controlled trial identified in this review, liquid fibrin sealant was applied directly to the suture line with a clear superior efficacy as it provided watertight closure of the durotomy in $92 \%$ versus $28 \%$ in the suture only group [29]. This feature allows the final closure of patient and perhaps a reduced surgical time, however this is not supported by the available data. However, these findings were not consistent with a reduced frequency of postoperative clinically relevant CSF leaks.

The definition of postoperative CSF leaks varied widely from extensive use of radio imaging with the identification of even small non clinically relevant fluid accumulations [29] to only evaluating clinical relevant CSF leaks (most of the reported studies). The clinical relevance of evaluating the effect of fibrin sealants on fluid accumulations detected with imaging such as 
magnetic resonance is doubtful [29]. The available evidence on the effect of fibrin sealants on clinically relevant postoperative CSF leaks is based mostly on lower evidence case series with the potential of bias. Nevertheless, and with the limitations of the identified clinical studies, fibrin sealants seemed to control the formation of postoperative CSF leaks in the supratentor$\mathrm{ial} /$ posterior fossa $[10,11,33,35,41,46,47,48,49,50,52]$, spinal $[32,39,40,45,51,56]$ and transsphenoidal [7, 34, 37, 42-44, 55] procedures. Importantly, fibrin sealants were used in a large variety of ways including directly on the suture line, on patches (sutured or non-sutured), together with haemostatic agents such as Surgicel and Gelfoam, and with several autologous tissues. Thus, a potential effect directly from the fibrin sealant used is difficult to confirm.

Only two papers, both case series, discussed the use of fibrin sealants as a treatment of persistent CSF leaks. In patients that had undergone endoscopically anterior skull base repair, high success rates were achieved after the closure of the CSF fistula with a combination of graft plus fibrin sealant plus Surgical [58], although it is difficult to assess the direct effect of fibrin sealant in these cases. In the analysis of 10 patients with persistent CSF fistulas after different operative approaches, fibrin sealant was injected directly into the fistula with full closure of all fistula [42].

The safety profile of fibrin sealant products has been tested over many decades. The randomized controlled trials reported in this systematic literature review $[24,29,32]$ were not able to detect specific adverse events with a higher frequency in the fibrin sealant group. In the group of case series analyzed, of which most were without any control groups, no consistent or repeated safety issue was detected. As summarized in Table 7, specific adverse events were reported as early as 1987 in 7 papers identifying 8 events in neurosurgical procedures. Most of these events were only assumed to be related to fibrin sealants. One event of gas emboli occurred after the use of the product with disregarding of the warnings for such risk [63]. One case of anaphylactic shock occurred after reexposure to the product and was confirmed with antibodies to product component [61].

The use of fibrin sealants imparts the possibility of local and/or systemic toxicity, allergic reactions, transmissible diseases, zoonosis, etc. Nevertheless, no such transmissible diseases have been reported and, in general, adverse effects have been very rarely reported in the pertinent literature, of which most were speculative.

Limitations to his systematic literature review include the limited number of randomized controlled studies that have been conducted to evaluate the effect of fibrin sealants on intraoperative dura closure as well as on postoperative cerebrospinal fluid leakage. It is unfortunate that the majority of what we identified was observational data including case series information that is inherently flawed. The need for high quality studies and clinical evidence in neurosurgery is essential. Recently, Mansouri and colleagues (2016) analyzed the quality of neurosurgical randomized controlled trials and also found a low prevalence of such analyses and a low quality of design and reporting with many study designs not compatible with the stated objectives [68]. While the authors did not imply that randomized controlled trials are not appropriate to neurosurgery evaluations, they did imply that all neurosurgical questions can be answered through a randomized controlled trial and that there is a need for other approaches. In situations where the conduct of a randomized controlled trial is not feasible, a proposed alternative is the conduct of well-designed prospective observational trials that adhere to as many of the principles of sound clinical research as possible [68].

Other limiting factors should be taken into consideration when evaluating the research question. One limitation is how surgery is often practiced. Specifically, surgery due to its nature is more "experience based" and less "evidence based". While drugs can be administered based on an established dose response relationship, many neurosurgical approaches have to be tailor made during surgery to fit the specific patient needs at the moment. As such, the best 
approaches in surgery are often published in case series based on a single or few surgeons experiences. These important techniques may be valuable for other surgeons to follow in order to treat the patients optimally although this is based on experience rather than evidence. In this systematic literature review we have to respect this paradigm and, as such, included data from publications other than randomized controlled trials such as from case series. Additionally, several types of fibrin sealants have been allowed to be evaluated in this review ranging from liquid fibrin sealant to that of the patch formulation, with this therapeutic heterogeneity impacting the generalizability of the findings. As the active components are the same (thrombin plus fibrinogen) the added patch might add a theoretical advantage over liquid fibrin sealant when large dura gaps are being treated. Fibrin sealant is rarely used alone and oftentimes allogeneic patches are used to reinforce the suture line and to close gaps. The allowance of all types of fibrin sealant type products did not allow for any comparisons between products, which may limit the overall significance of this work for the neurosurgical audience. Further, the degree of clinical heterogeneity in patients (age, sex, race, medical condition) and the use of secondary treatments (ie, medical therapies, interventional strategies) as well as the neurosurgical characteristics and the definitions of CSF leak intraoperatively versus postoperatively also limit our ability to generalize our findings. It is well established that the incidence of CSF leaks are dependent on patients, their disease, and neurosurgical characteristics and that the effects of fibrin sealants may differ significantly based on the type of surgery (ie, spinal, posterior fossa, pituitary). An additional limitation of our analysis was that very different techniques are used based on the experience of the neurosurgeon. These differences might influence the strength of concluding a potential observed effect of fibrin sealants in treating/preventing CSF leaks.

A previous meta-analysis has demonstrated that fibrin sealants either reduced blood loss or reduced the time to achieve haemostasis, and both such indicators were positively associated with a good surgical outcome [14]. This systematic literature review has evaluated the use of fibrin sealants to treat/reduce CSF leaks and the results seemed to indicate a reduction in intraoperative and postoperative fluid collections with an acceptable safety profile with the potential of reduced infection, wound problems, pseudomeningocele and pneumocephalus. Furthermore, this may prove to be cost-effective by reducing the incidence of CSF leakage. The strength of evidence identified in this systematic literature review can be strengthened further through additional well-designed and controlled clinical trials.

In summary, we found that of the 32 clinical studies identified, three were randomized controlled trials evaluating the efficacy of fibrin sealants in dura sealing $(n=149$ exposed to fibrin sealant). The effect of fibrin sealants in providing watertight closure of the dura suture line was demonstrated in one high quality randomized controlled trial. While there was a significantly higher rate of dura closure in the fibrin sealant than control group (92.1\% versus $38.0 \%)$, it is notable that the fibrin sealant group had a higher rate (although not statistically significant) of postoperative cerebrospinal fluid leakage ( $6.7 \%$ versus $2.0 \%$, respectively). Most clinical trials evaluated the effect of fibrin sealants in prevention of CSF leaks due to its sealing effect in very different surgical approaches. These are mostly lower level evidence studies that, with caution, may suggest a possible effect of fibrin sealants in preventing postoperative CSF leaks. Two small clinical studies (case series) evaluated the effect of using fibrin sealants in treating persisting leaks without firm conclusions on efficacy. Safety data was presented in the identified citations (including two citations reporting on a single trial) identified clinical studies where a total of 2935 patients had been exposed to fibrin sealants during a variety of neurosurgical procedures. Overall the safety profile with fibrin sealant usage is acceptable. Specific adverse reports where fibrin sealants have been used for dura sealing are very few with just 8 cases, most being of a speculative nature, reported since 1987. 
In this review, the majority of identified literature related to the use of the fibrin sealant, Tisseel. This is not unexpected as it has been marketed for over 3 decades. Overall, among the reviewed literature, it was evaluated in one report of acute CSF leaks [36], one randomized controlled trial [29], 11 case series of CSF leak prevention [7, 10, 11, 37, 40, 42, 45, 46, 48, 49, 50, 57], and in one subgroup of patients treated for persistent CSF leaks [42]. The extrapolation of the data derived from Tisseel/Tissucol studies to other fibrin sealants should be done with some degree of caution. Future well-designed and well-powered randomized controlled trials involving Tisseel as well as the other fibrin sealants will strengthen our ability to draw firm conclusions regarding the effectiveness of these agents. In the meantime, the availability and data derived from over 30 years of Tisseel use suggests that it may be considered as a standard part of the "surgical toolbox" when performing neurosurgical procedures where dura sealing is required.

\section{Conclusions}

The overall conclusion of our systematic literature review are that fibrin sealants used in neurosurgery may be beneficial in providing a watertight closure of the dura suture line and may have an effect in preventing CSF leaks with an acceptable safety profile. We caution that this is derived from findings of a single randomized controlled trial that was carried out under specific settings in patients undergoing elective craniotomy or craniectomy for pathological processes in the posterior fossa or in the supratentorial region and had demonstrated persistent CSF leakage from a primary attempt at suture closure of the dural incision. We emphasize that data from well-designed and powered randomized clinical trials are needed to further support these findings and firmly establish the efficacy of fibrin sealants providing intraoperative waterproof dura sealing as well as in limiting postoperative cerebrospinal leakage.

\section{Supporting Information}

S1 PRISMA 2009 Checklist. Prisma 2009 checklist completed form. Modified from: Moher D, Liberati A, Tetzlaff J, Altman DG, The PRISMA Group (2009). Preferred Reporting Items for Systematic Reviews and Meta-Analyses: The PRISMA Statement. PLoS Med 6(6): e1000097. doi:10.1371/journal.pmed1000097.

(DOC)

\section{Acknowledgments}

Felice Esposito has given some didactic presentations on Dural Sealing methods. Paolo Cappabianca received an unrestricted research grant from Baxter Italy and has given some didactic presentations on Dural Sealing methods. Peter Kruse was paid for this structured literature review as an independent clinical consultant. The funders had no role in study design, data collection and analysis, decision to publish, or preparation of the manuscript.

\section{Author Contributions}

Conceived and designed the experiments: FE PK PC. Performed the experiments: FE PK. Analyzed the data: FE. Contributed reagents/materials/analysis tools: FE PK. Wrote the paper: FE PK. Drafted the manuscript: FE PK. Performed the data analysis: FE FFA PK LMC DS. Corrected the proofs: FE FFA PK LMC DS VE FT PC. Approved the final form of the manuscript: FE FFA PK LMC DS VE FT PC. 


\section{References}

1. Becker SS, Jackler RK, Pitts LH. Cerebrospinal fluid leak after acoustic neuroma surgery: a comparison of the translabyrinthine, middle fossa, and retrosigmoid approaches. Otol Neurotol. 2003; 24:107-112. PMID: 12544038

2. Cappabianca P, Cavallo LM, Esposito F, Valente V, de Divitiis E. Sellar repair in endoscopic endonasal transsphenoidal surgery: Results of 170 cases. Neurosurgery. 2002; 51:1365-1371. PMID: 12445341

3. Fengbin Y, Xinyuan L, Xiaowei L, Xinwei W, Deyu C. Management and outcomes of cerebrospinal fluid leak associated with anterior decompression for cervical ossification of the posterior longitudinal ligament with or without dural ossification. J Spinal Disord Tech. 2013; doi: 10.1097/bsd. 0000000000000031

4. Merkus $P$, Taibah A, Sequino G, Sanna M. Less than $1 \%$ cerebrospinal fluid leakage in 1,803 translabyrinthine vestibular schwannoma surgery cases. Otol Neurotol. 2010; 31:276-283. doi: 10.1097/ MAO.0b013e3181cc06ad PMID: 20042905

5. Allen KP, Isaacson B, Kutz JW, Purcell PL, Roland PS. The association of meningitis with postoperative cerebrospinal fluid fistula. J Neurol Surg B Skull Base. 2012; 73:401-404. doi: 10.1055/s-00321329618 PMID: 24294557

6. Biroli F, Fusco M, Bani GG, Signorelli A, Esposito F, de Divitiis O, et al. Novel equine collagen-only dural substitute. Neurosurgery. 2008; 62:273-274. doi: 10.1227/01.neu.0000317404.31336.69 PMID: 18424997

7. Cappabianca P, Esposito F, Cavallo LM, Messina A, Solari D, di Somma LGM, et al. Use of equine collagen foil as dura mater substitute in endoscopic endonasal transsphenoidal surgery. Surgical Neurology. 2006; 65:144-149. PMID: 16427407

8. Cavallo LM, Messina A, Esposito F, de Divitiis O, Dal Fabbro M, de Divitiis E, et al. Skull base reconstruction in the extended endoscopic transsphenoidal approach for suprasellar lesions. J Neurosurg. 2007; 107:713-720. PMID: 17937213

9. Cavallo LM, Solari D, Somma T, Di Somma A, Chiaramonte C, Cappabianca P. Use of equine pericardium sheet (LYOMESH(R)) as dura mater substitute in endoscopic endonasal transsphenoidal surgery. TransI Med UniSa. 2013; 7:23-28. PMID: 24251248

10. Esposito F, Cappabianca P, Fusco M, Cavallo LM, Bani GG, Biroli F, et al. Collagen-only biomatrix as a novel dural substitute Examination of the efficacy, safety and outcome: Clinical experience on a series of 208 patients. Clin Neurol Neurosurg. 2008; 110:343-351. doi: 10.1016/j.clineuro.2007.12.016 PMID: 18242823

11. Esposito F, Grimod G, Cavallo LM, Lanterna L, Biroli F, Cappabianca P. Collagen-only biomatrix as dural substitute: What happened after a 5-year observational follow-up study. Clin Neurol Neurosurg. 2013; 115:1735-1737. doi: 10.1016/j.clineuro.2013.03.013 PMID: 23622936

12. Spotnitz WD, Burks S. Hemostats, sealants, and adhesives III: a new update as well as cost and regulatory considerations for components of the surgical toolbox. Transfusion. 2012; 52:2243-2255. doi: 10.1111/j.1537-2995.2012.03707.x PMID: 22612730

13. Tisseel: Package Insert and Label Information. Italian version, March 2013, in, 2013. http://druginserts. com/lib/other/meds/tissell-1.

14. Carless PA, Henry DA, Anthony DM. Fibrin sealant use for minimising peri-operative allogeneic blood transfusion. Cochrane Database Syst Rev. 2003; CD004171. PMID: 12804501

15. Lago Oliver J, Arjona Medina I, Martín García-Almenta E, Martín Gil J, Sanz Sánchez M, Pérez Díaz M, et al. Use of fibrin based biological adhesives in the prevention of anastomotic leaks in the high risk digestive tract: preliminary results of the multicentre, prospective, randomised, controlled, and simple blind phase IV clinical trial: Protissucol001. Cir Esp. 2010; 90:647-655.

16. Silecchia G, Boru CE, Mouiel J, Rossi M, Anselmino M, Tacchino RM, et al. Clinical evaluation of fibrin glue in the prevention of anastomotic leak and internal hernia after laparoscopic gastric bypass: preliminary results of a prospective, randomized multicenter trial. Obes Surg. 2006; 16:125-131. PMID: 16469211

17. Upadhyaya VD, Gopal SC, Gangopadhyaya AN, Gupta DK, Sharma S, Upadyaya A, et al. Role of fibrin glue as a sealant to esophageal anastomosis in cases of congenital esophageal atresia with tracheoesophageal fistula. World J Surg. 2007; 31:2412-2415. PMID: 17917772

18. Gonfiotti A, Santini PF, Jaus M, Janni A, Lococo A, De Massimi AR, et al. Safety and effectiveness of a new fibrin pleural air leak sealant: a multicenter, controlled, prospective, parallel-group, randomized clinical trial. Ann Thorac Surg. 2011; 92:1217-1225. doi: 10.1016/j.athoracsur.2011.05.104 PMID: 21958767 
19. Gopal SC, Gangopadhyay AN, Mohan TV, Upadhyaya VD, Pandey A, Upadhyaya A, et al. Use of fibrin glue in preventing urethrocutaneous fistula after hypospadias repair. J Pediatr Surg. 2008; 43:18691872. doi: 10.1016/j.jpedsurg.2008.04.022 PMID: 18926223

20. Suzuki Y, Kuroda Y, Morita A, Fujino Y, Tanioka Y, Kawamura T, et al. Fibrin glue sealing for the prevention of pancreatic fistulas following distal pancreatectomy. Arch Surg. 1995; 130:952-955. PMID: 7661678

21. D'Andrea AA, Costantino V, Sperti $C$, Pedrazzoli S. Human fibrin sealant in pancreatic surgery: it is useful in preventing fistulas? A prospective randomized study. Ital J Gastroenterol. 1994; 26:283-286. PMID: 7949264

22. Altomare DF, Greco VJ, Tricomi N, Arcana F, Mancini S, Rinaldi M, et al. Seton or glue for trans-sphincteric anal fistulae: a prospective randomized crossover clinical trial. Colorectal Dis. 2011; 13:82-86. doi: 10.1111/j.1463-1318.2009.02056.x PMID: 19832873

23. Grimaud JC, Munoz-Bongrand N, Siproudhis L, Abramowitz L, Senejoux A, Vitton V, et al. Fibrin glue is effective healing perianal fistulas in patients with Crohn's disease. Gastroenterology. 2010; 138:22752281, 2281 e2271. doi: 10.1053/j.gastro.2010.02.013 PMID: 20178792

24. Green AL, Arnaud A, Batiller J, Eljamel S, Gauld J, Jones P, Martin D, Mehdorn M, Ohman J, Weyns F. A multicentre, prospective, randomized, controlled study to evaluate the use of a fibrin sealant as an adjunct to sutured dural repair. Br J Neurosurg 2014; 12:1-7.

25. Lindsey I, Smilgin-Humphreys MM, Cunningham C, Mortensen NJ, George BD. A randomized, controlled trial of fibrin glue vs. conventional treatment for anal fistula. Dis Colon Rectum. 2002; 45:16081615. PMID: 12473883

26. Safan A, Shaker H, Abdelaal A, Mourad MS, Albaz M. Fibrin glue versus martius flap interpositioning in the repair of complicated obstetric vesicovaginal fistula. A prospective multi-institution randomized trial. Neurourol Urodyn. 2009; 28:438-441. doi: 10.1002/nau.20754 PMID: 19475577

27. Moher D, Liberati A, Tetzlaff J, Altman DG, Group P. Preferred reporting items for systematic reviews and meta-analyses: the PRISMA statement. BMJ. 2009; 339:b2535. doi: 10.1136/bmj.b2535 PMID: 19622551

28. Oxford Centre for Evidence-Based medicine-Levels of Evidence, 2009. Available at http://www.cebm. net/index.aspx?o=1025.

29. clinicaltrials.gov. NCT00681824-Fibrin sealant for the sealing of dura sutures. Results updated May 21, 2013 (Accessed May 2014).

30. clinicaltrials.gov. NCT01355627. Tasall-tTachoSil against liquor leak. (Accessed May 2014).

31. clinicaltrials.gov. NCT01174992. A study to evaluate the safety and effectiveness of EVICEI as an adjunct to sutured dural repair. (Accessed May 2014).

32. Nakamura H, Matsuyama $Y$, Yoshihara H, Sakai $Y$, Katayama $Y$, Nakashima S, et al. The effect of autologous fibrin tissue adhesive on postoperative cerebrospinal fluid leak in spinal cord surgery: a randomized controlled trial. Spine (Phila Pa 1976). 2005; 30:E347-351.

33. Than KD, Baird CJ, Olivi A. Polyethylene glycol hydrogel dural sealant may reduce incisional cerebrospinal fluid leak after posterior fossa surgery. Neurosurgery. 2008; 63:ONS182-187. doi: 10.1227/01 neu.0000335034.08274.d2 PMID: 18728598

34. Tamasauskas A, Sinkunas K, Draf W, Deltuva V, Matukevicius A, Rastenyte D, et al. Management of cerebrospinal fluid leak after surgical removal of pituitary adenomas. Medicina (Kaunas). 2008; 44:302-307.

35. Yoshimoto $\mathrm{T}$, Sawamura $\mathrm{Y}$, Houkin $\mathrm{K}$, Abe H. Effectiveness of fibrin glue for preventing postoperative extradural fluid leakage. Neurol Med Chir (Tokyo). 1997; 37:886-890.

36. Hobbs CG, Darr A, Carlin WV. Management of intra-operative cerebrospinal fluid leak following endoscopic trans-sphenoidal pituitary surgery. J Laryngol Otol. 2011; 125:311-313. doi: 10.1017/ S0022215110002483 PMID: 21106141

37. Cappabianca P, Cavallo LM, Valente V, Romano I, D'Enza AI, Esposito F, et al. Sellar repair with fibrin sealant and collagen fleece after endoscopic endonasal transsphenoidal surgery. Surg Neurol. 2004; 62:227-233. PMID: 15336865

38. Seda L, Camara RB, Cukiert A, Burattini JA, Mariani PP. Sellar floor reconstruction after transsphenoidal surgery using fibrin glue without grafting or implants: technical note. Surg Neurol. 2006; 66:46-49. PMID: 16793438

39. Parlato C, di Nuzzo G, Luongo M, Parlato RS, Accardo M, Cuccurullo L, et al. Use of a collagen biomatrix (TissuDura) for dura repair: a long-term neuroradiological and neuropathological evaluation. Acta Neurochir (Wien). 2011; 153:142-147.

40. Gazzeri R, Neroni M, Alfieri A, Galarza M, Faiola A, Esposito S, et al. Transparent equine collagen biomatrix as dural repair. A prospective clinical study. Acta Neurochir (Wien). 2009; 151:537-543. 
41. Murai $Y$, Mizunari T, Kobayashi S, Teramoto A. Surgical technique for the prevention of cerebrospinal fluid leakage after bifrontal craniotomy. World Neurosurg. 2014; 81:344-347. doi: 10.1016/j.wneu. 2013.01.032 PMID: 23314023

42. Cappabianca P, Esposito F, Magro F, Cavallo LM, Solari D, Stella L, et al. Natura Abhorret a Vacuouse of fibrin glue as a filler and sealant in neurosurgical "dead spaces". Technical note. Acta Neurochir Suppl (Wien). 2010; 152:897-904.

43. Van Velthoven V, Clarici G, Auer LM. Fibrin tissue adhesive sealant for the prevention of CSF leakage following transsphenoidal microsurgery. Acta Neurochir (Wien). 1991; 109:26-29.

44. Yin J, Su CB, Xu ZQ, Xia XW, Song F. Reconstruction of the sellar floor following transsphenoidal surgery using gelatin foam and fibrin glue. Chin Med Sci J. 2005; 20:198-201. PMID: 16261893

45. Jankowitz BT, Atteberry DS, Gerszten PC, Karausky P, Cheng BC, Faught R, et al. Effect of fibrin glue on the prevention of persistent cerebral spinal fluid leakage after incidental durotomy during lumbar spinal surgery. Eur Spine J. 2009; 18:1169-1174. doi: 10.1007/s00586-009-0928-6 PMID: 19283413

46. Kassam A, Horowitz M, Carrau R, Snyderman C, Welch W, Hirsch B, et al. Use of Tisseel fibrin sealant in neurosurgical procedures: incidence of cerebrospinal fluid leaks and cost-benefit analysis in a retrospective study. Neurosurgery. 2003; 52:1102-1105. PMID: 12699553

47. Kurschel S, Ono S, Oi S. Risk reduction of subdural collections following endoscopic third ventriculostomy. Childs Nerv Syst. 2007; 23:521-526. PMID: 17221272

48. Parker SR, Harris P, Cummings TJ, George T, Fuchs H, Grant G. Complications following decompression of Chiari malformation Type I in children: dural graft or sealant? J Neurosurg Pediatr. 2011; 8:177183. doi: 10.3171/2011.5.PEDS10362 PMID: 21806360

49. Gazzeri R, Galarza M, Alfieri A, Neroni M, Roperto R. Simple intraoperative technique for minor dural gap repair using fibrin glue and oxidized cellulose. World Neurosurg. 2011; 76:173-175. doi: 10.1016/j. wneu.2010.09.029 PMID: 21839970

50. Gillman GS, Parnes LS.: Acoustic neuroma management: a six-year review. J Otolaryngol. 1995; 24:191-197. PMID: 7674446

51. Hida K, Yamaguchi S, Seki T, Yano S, Akino M, Terasaka S, et al. Nonsuture dural repair using polyglycolic acid mesh and fibrin glue: clinical application to spinal surgery. Surg Neurol. 2006; 65:136-143. PMID: 16427404

52. Reddy M, Schoggl A, Reddy B, Saringer W, Weigel G, Matula C. A clinical study of a fibrinogen-based collagen fleece for dural repair in neurosurgery. Acta Neurochir (Wien). 2002; 144:265-269.

53. Reddy M, Schöggl A, Reddy B, Holzer A, Saringer W, Steiger C, et al. Watertightness and effectiveness of a fibrinogen-based collagen fleece $\left(\right.$ TachoComb $^{\mathbb{R}}$ ) in neurosurgery. Euro Surg 2003; 35:278-281.

54. Nistor RF, Chiari FM, Maier $\mathrm{H}$, Hehl K. The fixed combination of collagen with components of fibrin adhesive-a new hemostypic agent in skull base procedures. Skull Base Surg. 1997; 7:23-30. PMID: 17171003

55. Cho JM, Ahn JY, Chang JH, Kim SH. Prevention of cerebrospinal fluid rhinorrhea after transsphenoidal surgery by collagen fleece coated with fibrin sealant without autologous tissue graft or postoperative lumbar drainage. Neurosurgery. 2011; 68:130-137. doi: 10.1227/NEU.0b013e318207b4ea PMID: 21206312

56. Black P: Cerebrospinal fluid leaks following spinal surgery: use of fat grafts for prevention and repair. Technical note. J Neurosurg. 2002; 96:250-252. PMID: 12450290

57. Weber R, Keerl R, Draf W, Schick B, Mosler P, Saha A. Management of dural lesions occurring during endonasal sinus surgery. Arch Otolaryngol Head Neck Surg. 1996; 122:732-736. PMID: 8663945

58. Cassano M, Felippu A. Endoscopic treatment of cerebrospinal fluid leaks with the use of lower turbinate grafts: a retrospective review of 125 cases. Rhinology. 2009; 47:362-368. doi: 10.4193/Rhin08.175 PMID: 19936359

59. Higgins JPT, Altman DG (Eds). Chapter 8: Assessing risk of bias in included studies. In: Higgins JPT, Green S (Eds). Cochrane Handbook for Systematic Reviews of Interventions. The Cochrane Collaboration, 2008. Available at www.cochrane-handbook.org.

60. Schulz KF, Grimes DA. Allocation concealment in randomized trials: defending against deciphering. Lancet 2002; 359: 614-618. PMID: 11867132

61. Beierlein W, Scheule AM, Antoniadis G, Braun C, Schosser R. An immediate, allergic skin reaction to aprotinin after reexposure to fibrin sealant. Transfusion. 2000; 40:302-305. PMID: 10738030

62. Czepko R, Kwinta B.The use of TachoComb for the rhinorrhea repair in pituitary transsphenoidal surgery. Polim Med. 2006; 36:3-9. 
63. Felema GG, Bryskin RB, Heger IM, Saswata R. Venous air embolism from Tisseel use during endoscopic cranial vault remodeling for craniosynostosis repair: a case report. Paediatr Anaesth. 2013; 23:754-756. doi: 10.1111/pan.12180 PMID: 23746210

64. Handa J, Koyama T. Use of fibrin glue (Beriplast $P$ ) in neurosurgical practice. Nihon Geka Hokan. 1989; 58:231-235. PMID: 2802921

65. Kanazawa $\mathrm{R}$, Sato S, Iwamoto N, Teramoto A. Allergic reaction following arachnoid plasty with a fibrin sealant. Neurol Med Chir (Tokyo). 2010; 50:608-610.

66. Schlenker M, Ringelstein EB. Epidural fibrin clot for the prevention of post-lumbar puncture headache: a new method with risks. J Neurol Neurosurg Psychiatry. 1987; 50:1715. PMID: 2449515

67. Wakamoto H, Miyazaki H, Orii M, Ishiyama N, Akiyama K, Konohana I. Aseptic meningitis as a complication caused by an allergic reaction after microvascular decompression: two case reports. No Shinkei Geka. 2002; 30:1331-1335. PMID: 12491585

68. Mansouri A, Cooper B, Shin SM, Kondziolka D. Randomized controlled trials and neurosurgery: the ideal fit or should alternative methodologies be considered? J Neurosurg 2016; 124:558-568. doi: 10. 3171/2014.12.JNS142465 PMID: 26315006 